\title{
Your Science Conference Should Have a Code of Conduct
}

\author{
Brett Favaro ${ }^{1,2 *}$, Samantha Oester ${ }^{3}$, John A. Cigliano ${ }^{4}$, Leslie A. Cornick ${ }^{5}$, \\ Edward J. Hind ${ }^{6}$, E. C. M. Parsons ${ }^{3}$ and Tracey J. Woodbury ${ }^{7}$ \\ ${ }^{1}$ School of Fisheries, Fisheries and Marine Institute of Memorial University of Newfoundland, St. John's, NL, Canada, \\ ${ }^{2}$ Department of Ocean Sciences, Memorial University of Newfoundland, Logy Bay, NL, Canada, ${ }^{3}$ Department of \\ Environmental Science and Policy, George Mason University, Fairfax, VA, USA, ${ }^{4}$ Department of Biological Sciences, \\ Environmental Conservation Program, Cedar Crest College, Allentown, PA USA, ${ }^{5}$ Department of Marine and Environmental \\ Sciences, Alaska Pacific University, Anchorage, AK, USA, ${ }^{6}$ Department of Sociology, Manchester Metropolitan University, \\ Manchester, UK, ${ }^{7}$ Society for Human Resource Management, Alexandria, VA, USA
}

Keywords: abuse, bullying, human resources, inclusivity, safety, harassment

\section{OPEN ACCESS}

Edited by:

Ellen Hines,

San Francisco State University, USA

Reviewed by:

Eleanor Sterling,

American Museum of Natural History,

USA

Janet Stemwedel,

San Jose State University, USA

${ }^{*}$ Correspondence:

Brett Favaro

brett.favaro@mi.mun.ca

Specialty section:

This article was submitted to

Marine Conservation and

Sustainability,

a section of the journal

Frontiers in Marine Science

Received: 25 April 2016

Accepted: 07 June 2016

Published: 22 June 2016

Citation:

Favaro B, Oester S, Cigliano JA, Cornick LA, Hind EJ, Parsons ECM and Woodbury TJ (2016) Your Science

Conference Should Have a Code of

Conduct. Front. Mar. Sci. 3:103.

doi: 10.3389/fmars.2016.00103
Science conferences are a critical component of the scientific enterprise. They give us opportunities to present our research, to network and create future career opportunities, and to recruit researchers to our teams (Parsons, 2015). Many fruitful collaborations have spawned from chance meetings at conferences, and doubtless innumerable conservation solutions have stemmed from conversations over coffee at these important events. Therefore, whenever there is inequity of access to science conferences, the entire discipline suffers. Conservation science is tasked with saving the Earth's biodiversity, so for us, inequity means the biosphere suffers as well. But most importantly, individuals who are passionate about conservation can be driven out of the field due to disillusion and distrust.

The accessibility of any event is determined in part by how safe it is to attend, and safety is tied closely to one's gender, gender identity, sexual orientation, race, religion, and other factors. While this is uncomfortable to acknowledge, science continues to experience cases of harassment, intimidation, bullying, and discrimination. Recently, the United States' National Science Foundation released a statement making clear that they will not tolerate harassment at grantee institutions, encouraged reporting, and indicated a readiness to terminate funding to institutions that do not comply with national discrimination legislation (NSF, 2016).

Harassment in science should be tackled head-on, whether it occurs in conferences, fieldwork, or in any other aspect of the scientific enterprise (e.g., Clancy et al., 2014). In the field of astronomy, students, staff, and faculty have all reported avoiding conferences and other events due to feeling unsafe (Richey et al., 2015). While we do not have comparable data for conservation biology conferences, our own experiences, as well as accounts by our close friends and colleagues, suggest that our discipline needs to improve as well. Parsons (2015) for example reports witnessing numerous unsavory events at biological conferences (including conservation biology meetings) such as: delegates stealing and damaging property, many instances of verbal abuse (including racist and sexist comments), drug taking and dealing, drunken brawls, and instances of sexual harassment. An incident of a conference delegate throwing a metal mug at the head of a volunteer is also recounted.

Most workplaces have explicit anti-harassment policies, while conferences often do not (Settles and O'Connor, 2014). We feel this represents an unacceptable gap given the importance of conference attendance in expanding career opportunities. As organizers of the 4th International Marine Conservation Congress (IMCC4, St. John's NL, July 30-Aug 3 2016) and the associated OceansOnline conference (Aug 4, 2016), we are taking steps to create an environment where inclusiveness is encouraged and embraced, and harassment and bullying are explicitly disallowed. To this end, we have drafted a code of conduct that guides acceptable and unacceptable behavior at the event (SCB, 2016). This code has been reviewed 
by a service sector professional with a background in inclusivity (Kathy Hawkins, Manager, Inclusion NL, pers. comm).

According to the Society for Human Resource Management (2014), codes of conduct should not be viewed as disciplinary tools, though discipline may be called for in certain instances. Instead, codes of conduct should give guidance and set boundaries for productive behavior, rather than exhaustively defining possible infractions and dictating specific punishments. Codes of conduct are meant to lay the groundwork for creating open and inclusive environments that foster positive discussions and encourage all participants to consider the viewpoints of those individuals who might otherwise be overshadowed by a more boisterous or mainstream voice.

The IMCC4 code guides the expected, professional behavior of delegates, such as:

- Treating everyone with respect and consideration;

- Communicating openly and thoughtfully with others and being considerate of the multitude of views and opinions that are different than your own;

- Being respectful and mindful in your critique of ideas;

- Being mindful of your surroundings and of your fellow participants.

It also suggests what behaviors are considered to be unacceptable, notably:

- Harassment and intimidation, including any verbal, written, or physical conduct designed to threaten, intimidate, or coerce another delegate, conference organizers, or staff;

- Discrimination based on gender or gender identity, sexual orientation, age, disability, physical appearance, body size, race, religion, national origin, or culture;

- Physical or verbal abuse of any attendee, speaker, volunteer, exhibitor, staff member, service provider or other meeting guest;

- Disrespectful disruption of presentations.

The following examples of inappropriate behavior, based on descriptions by the Society for Human Resource Management (2014), are intended to be guidelines and are not exclusive when determining whether there has been a violation of this policy:

- Verbal harassment includes comments that are offensive or unwelcome regarding a person's nationality, origin, race, color, religion, gender, gender identity, sexual orientation, age, body, disability or appearance, including epithets, slurs, and negative stereotyping.

- Nonverbal harassment includes distribution, display, or discussion of any written or graphic material that ridicules, denigrates, insults, belittles, or shows hostility, aversion, or disrespect toward an individual or group because of national origin, race, color, religion, age, gender, sexual orientation, pregnancy, appearance, disability, sexual identity, marital or other protected status.

Inappropriate conference behavior also includes inappropriate use of nudity and/or sexual images in public spaces or in presentations; threatening or stalking any participant; sexually harassing any participant; attempting to bully conference staff or volunteers; sending emails to conference staff or members of the organizing committee that include harassment, bullying, or intimidation (SCB, 2016). Verbal or written taunting (including but not limited to sexual, racial, or ethnic slurs) that, in the attendee's opinion, impairs their ability to perform their job is included in the definition of harassment (Society for Human Resource Management, 2014).

Our code has procedural teeth. There are three core consequences if it is violated (SCB, 2016):

- Anyone requested to stop unacceptable behavior is expected to comply immediately;

- IMCC4 staff (or their designee) or security may take any action deemed necessary and appropriate, including immediate removal from the meeting without warning and potentially without refund;

- SCB and the SCB Marine Section reserve the right to prohibit attendance at any future meeting if it is felt the future safety of delegates would be at risk.

Anonymity for both parties in an incident is important. False allegations of impropriety can damage careers. Likewise, reporting instances can potentially lead to career-harming retribution. Delegates need to have safe means to report problems that ensure anonymity for all involved (Parsons, 2015). IMCC4 will be staffed at all times by a security guard. For delegates who wish to lodge a complaint of harassment or other inappropriate behavior, a Safety Officer will be available and readily identifiable. The Safety Officer at IMCC4 will have a background in human resource management and professional training and experience in dealing with these issues. All discussions will be managed in a physical space without significant foot traffic from the conference, to provide privacy. The Safety Officer will discuss the incident with the delegate lodging an inquiry or complaint, as well as the steps that may need to be taken to make the delegate feel safe.

The Safety Officer is also training IMCC4 conference organizers to handle situations of inappropriate behavior. Training includes in-person workshops, reference material, and role-playing scenarios. In the event that a complaint is lodged and immediate physical safety is not a concern, the Safety Officer will convene a group of conference organizers to discuss steps that need to be taken. If mediation is needed between delegates, the Safety Officer will provide it.

It is important to point out that the presumption of innocence is not appropriate in guiding decisions about conference safety, including removing participants when there is an immediate risk of physical harm, because the primary responsibility is to keep delegates safe. There are plenty of behaviors that we all would agree should constitute ejection from a conference in the absence of definitive proof. Egregious behaviors such as striking another delegate, groping, sexual assault, hate speech, or other forms of clearly unacceptable behavior, should be met with a rapid response to ensure an immediate removal of risk to delegates. 
Conference organizers retain the right to take any actions necessary to maintain a welcoming environment for delegates and staff. This may include expulsion. The conference security guard or Safety Officer may remove the offender. An independent ombudsman who is trained in dealing with harassment and similar issues, and who has knowledge of the legal ramifications of allegations is essential (Parsons, 2015). This position provides delegates an opportunity to lodge any complaints they may have about being ejected, but will be managed outside of the conference organizers. The Safety Officer will provide contact information of the ombudsman to a delegate who is ejected from the conference, to be used at their discretion.

If delegates consider our code of conduct to be too stringent, then they need not attend our events. We are transparent with our expectations, and feel they reflect the best-practice recommendations for creating inclusive environments. Many professional scientific societies are developing similar codes of conduct, and our code owes much to the efforts and guidelines produced by the American Astronomical Society, a professional society that has been particularly active in combating harassment (e.g., AAS, 2016). The President of The Society for Marine Mammalogy also announced at the December 2015 members' meeting that they will be developing a similar code of conduct for their meetings. IMCC4 registrants will be required to agree to the code of conduct prior to completing registration. Conservation scientists understand the concept of the precautionary principle; this is simply exercising precaution when it comes to potential harm to our delegates. Harassment directly impacts careers and forces victims out of the discipline (Gewin, 2015; Anonymous, 2016). Conservation cannot afford this, and our consciences cannot abide it.

The principal guiding IMCC4 is to make marine science matter. But scientists, conservationists, students, and other delegates need to feel confident in a safe environment to present work, voice opinions, network, and make connections to truly help make marine science matter. Our hope is that the existence of the code of conduct means we will never have to deploy its consequences on delegates. We do not wear seatbelts because we expect to get into a car crash-we wear them because if a crash does happen, we want to be protected. That is the purpose of our code of conduct: to demonstrate that ours is an inclusive event, and that as organizers we will do everything in our power to make it a safe, open, welcoming space to all delegates. Harassment,

\section{REFERENCES}

AAS (2016). "Inclusive astronomy 2015, the Nashville recommendations," in 227th Meeting of the American Astronomical Society. Floria: Kissimee. Available online at: https://vanderbilt.app.box.com/s/kqtkj9l0qzphfhr63q6z 36ra8je9sbw9 (Accessed February 2016).

Anonymous (2016). Sexual harassment must not be kept under wraps. Nature 529:257. doi: 10.1038/529257a

Clancy, K. B. H., Nelson, R. G., Rutherford, J. N., and Hinde, K. (2014). Survey of academic field experiences (SAFE): trainees report harassment intimidation, bullying, and discrimination ideally should be rare or nonexistent, and means of reporting incidents should be safe and accessible.

Science is inherently a hierarchical community (professors, post-doctoral researchers, graduate students, etc.) but it doesn't follow that access to science and professional conferences should be hierarchical. At a time when societies, such as the Society for Conservation Biology, are working to increase diversity within their membership, we must do whatever we can to make conferences accessible or else human diversity within the discipline will suffer. It is well-documented that diversity improves the quality of scientific research (Freeman and Huang, 2014), so if our science spaces are inaccessible, then the work that we do to support Earth's biodiversity will suffer as well. An important step toward equal access is for every conference to have a code of conduct that provides guidance on what is and is not acceptable behavior at the event. This is what we hope to achieve with the code of conduct for IMCC4 and OceansOnline-a safe, inclusive space for our delegates to make marine science matter. We call on organizers of all conferences to develop similar codes to ensure that their conferences do the same.

\section{AUTHOR CONTRIBUTIONS}

All authors contributed to each of the following components of authorship: Substantial contributions to the conception or design of the work; or the acquisition, analysis, or interpretation of data for the work; Drafting the work or revising it critically for important intellectual content; Final approval of the version to be published; Agreement to be accountable for all aspects of the work in ensuring that questions related to the accuracy or integrity of any part of the work are appropriately investigated and resolved.

\section{FUNDING}

Open Access publication fees were paid for by the Memorial University Library Open Access Author's Fund.

\section{ACKNOWLEDGMENTS}

We wish to thank Kathy Hawkins, manager for Inclusion NL, for reviewing our code of conduct. 
Parsons, E. C. M. (2015). So you think you want to run an environmental conservation meeting? Advice on the slings and arrows of outrageous fortune that accompany academic conference planning. J. Environ. Stud. Sci. 5, 735-744. doi: 10.1007/s13412-0150327-8

Richey, C. R., Clancy, K. B. H., Lee, K. M., and Rodgers, E. (2015). The CSWA Survey on Workplace Climate and an Uncomfortable Conversation about Harassment. Available online at: http://bit.ly/Richey_2015_Masursky_ Talk (Accessed January 2016).

SCB (2016). Code of Conduct for the International Marine Conservation Congress. Society for Conservation Biology. Available from http://conbio.org/minisites/imcc-2016/registration-participation/code-of-conduct/ (Accessed March 2016).

Settles, I. H., and O'Connor, R. C. (2014). Incivility at academic conferences: gender differences and the mediating role of climate. Sex Roles 71, 71-82. doi: 10.1007/s11199-014-0355-y
Society for Human Resource Management (2014). Harassment: Anti-Harassment Policy and Complaint Procedure. Society for Human Resource Management. Available online at: http://www.shrm.org/templatestools/samples/policies/ pages/cms_000534.aspx\#sthash.74qAPgx9.dpuf (Accessed February 2016).

Conflict of Interest Statement: The authors declare that the research was conducted in the absence of any commercial or financial relationships that could be construed as a potential conflict of interest.

Copyright (c) 2016 Favaro, Oester, Cigliano, Cornick, Hind, Parsons and Woodbury. This is an open-access article distributed under the terms of the Creative Commons Attribution License (CC BY). The use, distribution or reproduction in other forums is permitted, provided the original author(s) or licensor are credited and that the original publication in this journal is cited, in accordance with accepted academic practice. No use, distribution or reproduction is permitted which does not comply with these terms. 